\title{
Determined Efficiency Of Determine Apricot Constitution
}

\author{
V. Zavion \\ Department Of Horticulture And Forestry, University Of Athens Greece
}

\begin{abstract}
:
Determined Efficiency and some correlations between growth and Efficiency were evaluated in a set of 24 apricot Constitution. Even though the planting stock came from the same nursery, was of even age and on the same rootstock, the tree size of constitution varied from planting to a permanent site. Differences in the tree size of constitution slightly diminished over the six-year period, likely under the influence of uniform pruning used for all trees. Nevertheless, tree size evaluated from the area of stem cross-section can be considered as a genotype disposition. It is proved by a positive, highly significant correlation $(r=0.84++)$ between the rank constitution according to the area of stem cross-section in the fourth and eleventh year after planting. Confidence intervals also confirmed significance of differences in Determined Efficiency. In total, Determined Efficiency of twelve Constitution was significantly higher than in the control cultivar Velkopavlovická. A negative, significant moderate correlation $(r=-0.40+)$ was calculated between tree size and Determined Efficiency expressed as yield weight per unit area of stem cross-section. Weakly growing Constitution had higher Determined Efficiency. The highest Determined Efficiency was recorded in cultivars Vynoslivyj and Priusadebnyj and in LE-1321 and LE-390 hybrids.
\end{abstract}

Keywords: apricot; genotype; tree size; Determined Efficiency

\section{Introduction}

Efficiency is one of the basic production characteristics of apricot Constitution. Generally, it is average weight of yield in $\mathrm{kg}$ per tree or per hectare over a period. Annual weight of yield in $\mathrm{kg} /$ tree or cumulative weight of yield over a period calculated per unit area of stem cross-section (e.g. per $\mathrm{mm} 2$ ) provide easier comparability of results. It is so called Determined Efficiency. While Determined Efficiency is evaluated relatively frequently in some fruit tree species (e.g. in appletrees), few results are available in apricots. Sometimes weight of yield in $\mathrm{kg} / \mathrm{tree}$ and tree size (stem girth, area of stem cross-section, crown diameter or crown volume) are deter-mined in apricots separately but they are not correlated as Determined Efficiency. The rank of cultivars according to yield weight in $\mathrm{kg} /$ tree and Determined productivity is not identical. FAJT et al. 


\section{THE AMERICAN JOURNAL OF}

\section{RESEARCH}

(1999), who evaluated 16 apricot cultivars, reported the highest weight of yield in kg per tree in Giada and Sun giant while the evaluation according to Determined Efficiency ranked the cultivars as follows: Haggard, Layout, Sun giant and Giada. A similar conclusion was drawn by VACHŮN (1998) in a set of 11 cultivars. In his experiment Vynoslivyj, Priusadebnyj, Volšebnyj and Lenovo were the best by yield weight in kg per tree but the rank according to Determined Efficiency was Lenovo, Priusadebnyj, Vynoslivyj and Volšebnyj. The objective of the present paper was to evaluate tree size and Efficiency in a determine set of apricot genotypes over a six-year period, and to assess Determined Efficiency as a synthetic indicator for selection of suitable Constitution for growing or further breeding.

\section{MATERIAL AND METHOD}

The evaluated collection comprised 24 apricot genotypes. Some cultivars were bred in the Czech Republic, other cultivars were received from the Slovak Republic, Canada and Ukraine. Numerals after genotype names designate clones and/or breeder's number. Determine crossbreds (hybrids) are designated by working numbers only, LE and $M$ indicate the origin from Mendel University of Agriculture and Forestry at Brno, Faculty of Horticulture at Led nice. Velkopavlovická LE-6/2 is a control cultivar.

Five trees of each genotype were evaluated individually over the whole experimental period. Only exceptionally was the number of evaluated trees lower in some Constitution at the end of experiment. Commercial harvests started from the fourth year after planting in 1994. Identical cultural practices and protection measures were carried out on the plot during the six-year period of observations. No fruit thinning were used to regulate Efficiency in a special way. Pruning of all planted trees was identical. Sit's summer pruning was used in the first years after planting. Contour mechanical uniform pruning with a cutter bar was performed in the second half of August since the fourth year. Selective maintenance pruning with scissors was carried out in the flushing period. Even though long-term data on average temperatures and rainfall are favorable for the experimental locality and evaluated fruit-tree species $\left(9^{\circ} \mathrm{C}, 526 \mathrm{~mm}\right)$, the particular years showed significant differences in temperature course and rainfall sums in the blooming period, which resulted in Efficiency flu actuations. The characteristics and detailed description of weather conditions, temperature variations and rainfall and their risks in particular years of the period of observations are given in another paper.

\section{RESULTS AND DISCUSSION}

Differences in tree size between the Constitutions were significant in the fourth year after planting (at the beginning of the period of observations) as well as at the end of the period of observations (in the eleventh year after planting). It is confirmed by the values of stem cross- 


\section{THE AMERICAN JOURNAL OF}

\section{RESEARCH}

section shown in Table 1. Differences in the tree size of Constitution slightly diminished with increasing age (Fig. 1). Uniform contour pruning used in the orchard could be one of the reasons. In spite of this trend of diminishing differences it is to state that different tree size is a genotype disposition. Constitution growing vi-gloriously at the beginning of the experiment had greater tree sizes also at the end of the period of observations. It is demonstrated by a significant coefficient of correlation between the genotype rank according to the area of stem cross-section in 1994 and in $1999(r=0.84++)$. The control cultivar Velkopavlovická LE-6/2 had an average tree size in the set. A significant negative correlation between the tree size of apricot Constitution and Determined Efficiency was calculated for the studied collection $(r=-0.40+)$. With less vigorous growth Determined Efficiency significantly increased. It indicates that the weaker growth of genetype was at least partly influenced by its higher productivity (Fig. 4). A positive, highly significant correlation was established between the sum of yields in $\mathrm{kg}$ per tree over six years and Determined Efficiency in kg per unit area over this period (Fig. 5). Determined Efficiency was highest in Vynoslivyj, Priusadebnyj, LE-390, LE-1321 and Sem. Bademerik. Moreover, Vynoslivyj $\mathrm{cv}$. has good quality of fruits, mean fruit weight $(47 \mathrm{~g})$ and later time of fruit ripening (11 days after Velkopavlovická cv.). An application should be filed to include Vynoslivyj cv. in registration tests and to grow it in the conditions of this country. Priusadebnyj is a cultivar with extraordinary earliness but smaller fruits. It is important for growing in gardens and for breeding.

\section{References}

FAJT N., KOMPARA H., USENIK V., 1999. Agronomic yield and quality evaluation of 16 apricot cultivars in coastal Slovenia. Convene national "La cloture dell albicocco“, Meta-Ponto, Italia, 24. Italus-Hortus, 6: 113-114.NITRANSKÝ Š., 1992. Klasifikátor - Descriptor list - GenusArmeniaca P. Mill. Paha, VÚRV: 29.PAPANIKOLAOU-PAVLOPOULOU X., POULIS J., KA-RAYIANNIS I., 1999. Evaluation of fourteen (14) different apricot varieties at the Agricultural Research Station of Rhodes. Proc. of the XI International Symposium on Apricot Culture, Veria-Makedonia, 